\title{
NavegaFeliz: software educativo para auxílio das vítimas de escalpelamento da Classe Hospitalar
}

\author{
Larissa Sato Elisiário', Vitor Pinheiro Alves² \\ ${ }^{1}$ Instituto Ciberespacial - Universidade Federal Rural da Amazônia (UFRA) \\ Avenida Presidente Tancredo Neves, No 2501-Belém - PA - Brazil \\ ${ }^{2}$ EBI Informática - Belém - PA - Brazil \\ larissa.sato@ufra.edu.br, vitoreebi.com.br
}

\begin{abstract}
NavegaFeliz is a software specially developed for the reality of Amazonian riverside communities facing scalping accident - people who have scalp wholly or partially extracted accidentally for axes of boat engines that are not properly protected. Originally developed for use as an educational tool in the Hospital Class at Fundação Santa Casa de Misericórdia do Pará, the software is efficient in its use not only for children but adults who are undergoing treatment at the Foundation, being used as an educational tool, therapeutic tool and digital inclusion tool.
\end{abstract}

Resumo. O NavegaFeliz é um software desenvolvido especialmente para a realidade amazônica de comunidades ribeirinhas que enfrentam o acidente de escalpelamento - pessoas que têm o couro cabeludo total ou parcialmente extraído acidentalmente por eixos de motores de barco que não são devidamente protegidos. Desenvolvido originalmente para ser utilizado como ferramenta educacional nas aulas da Classe Hospitalar da Fundação Santa Casa de Misericórdia do Pará, o software se mostrou eficiente em sua utilização não só por crianças, mas adultos que estão em tratamento na Fundação, sendo utilizado como ferramenta educacional, terapêtica e de inclusão digital.

\section{Considerações iniciais}

A Amazônia, batizada pelo fotógrafo Pedro Martinelli (2000) de "O Povo das Águas", possui uma localização geográfica em que boa parte de suas estradas são rios, como afirmam os poetas paraenses Paulo André e Ruy Barata em seu poema "Esse Rio é Minha Rua", que diz: "Esse rio é minha rua, minha e tua mururé, piso no peito da lua, deito no chão da maré".

Nesta região encontram-se muitos ribeirinhos, pessoas que moram às margens dos rios e que possuem embarcações como principal meio de transporte. Essas embarcações muitas vezes possuem motores cujo eixo acaba ficando exposto, sem o uso da proteção obrigatória. Ao ficar exposto, o eixo do motor pode causar o acidente do escalpelamento.

O escalpelamento é um acidente que ocorre principalmente em meninas e mulheres que andam nos barcos com seus cabelos longos e soltos, pois os prendem no 
eixo do motor que está em rotação e este acaba por arrancar total ou parcialmente o couro cabeludo da vítima, trazendo sequelas profundas tanto do ponto de vista físico quanto psicológico.

No Estado do Pará, o local de referência para atendimento às vítimas do escalpelamento é a Fundação Santa Casa de Misericórdia do Pará - FSCMPA, um hospital-escola localizado na cidade de Belém, capital do estado, que atua de acordo com a Política Nacional de Humanização - PNH criada pelo Ministério da Saúde em 2003.

Consciente das necessidades físicas e psicológicas das vítimas, a FSCMPA possui ações de tratamento ambulatorial e hospitalar realizadas por uma equipe multiprofissional e interdisciplinar que envolve médicos, enfermeiros, psicólogos, fonoaudiólogos e assistentes sociais, bem como oferece atendimento pela Classe Hospitalar, que é uma escola que funciona dentro do hospital e atende crianças que ficam internadas por muito tempo e estão em idade escolar para que possam fazer o tratamento sem prejuízo de suas atividades escolares.

Em função de todo o sofrimento e dificuldades enfrentadas pelas vítimas de escalpelamento, foi elaborado um software educativo, com o apoio da Fundação de Amparo à Pesquisa do Estado do Pará - FAPESPA, especialmente voltado a esse público: o NavegaFeliz. A proposta do software está de acordo com Beckman e Santos (2004, p. 29) quando afirmam que "[...] através do brincar, pode-se coletar dados elementares da vítima de escalpelamento, tais como: emoções, interação com as outras pessoas, agressividade, desempenho físico-motor, nível lingüístico, formação moral e estágio de desenvolvimento".

O objetivo do software originalmente era auxiliar as crianças escalpeladas internadas na FSCMPA no resgate da autoestima e nas atividades escolares desenvolvidas através da Classe Hospitalar. Entretanto, ao ser aplicado, seu públicoalvo foi ampliado e incluiu também mulheres escalpeladas, adolescentes vítimas de abuso sexual e crianças que necessitavam de avaliação fonoaudiológica.

\section{II - Um pouco de história}

Durante a gestão da Governadora Ana Júlia Carepa (2007-2010) houve um esforço enorme para diminuir as taxas de escalpelamento no Estado do Pará, através da doação de protetores para o eixo dos motores, campanhas de prevenção, bem como mutirões de tratamento às vítimas de escalpelamento.

Neste mesmo período, o Governo investiu na implantação de Infocentros, centros públicos de acesso à Internet espalhados pelo Estado, através de um Programa

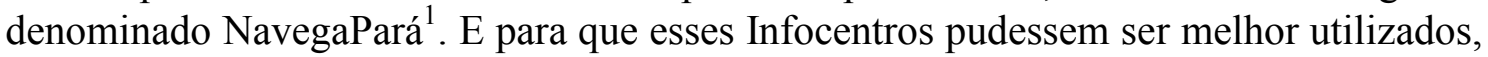
foram abertos editais de financiamento de projetos de produção de conteúdos e metodologias que pudessem auxiliar em sua utilização pela população.

O NavegaFeliz é, então, resultado de um destes editais, financiado pela FAPESPA, que levou um grupo de professores e alunos do Centro Universitário do Estado do Pará - CESUPA a aliar a necessidade de uso dos Infocentros ao apoio e

\footnotetext{
${ }^{1}$ Maiores informações sobre o Programa podem ser acessadas em www.navegapara.pa.gov.br
} 
tratamento das vítimas de escalpelamento, ambas as ações ligadas a políticas públicas estaduais naquele momento.

O Infocentro da FSCMPA passou, então, a ser utilizado com as crianças tanto para que aprendessem informática básica, quanto para que pudessem utilizar o computador como uma ferramenta de auxílio nas atividades da Classe Hospitalar, uma vez que este é um recurso lúdico motivador e que possui características que facilitam o processo ensino-aprendizagem.

Assim, a professora responsável pelo projeto, que atua com Tecnologias Educacionais, ao ter contato com a Classe Hospitalar e com as crianças vítimas de escalpelamento que na época estavam sob tratamento na FSCMPA, vislumbrou a possibilidade de desenvolver uma ferramenta que pudesse ser usada no Infocentro da própria FSCMPA para auxiliar estas crianças em seu tratamento e em seu desenvolvimento pedagógico.

A partir daí várias visitas foram realizadas, estudos, pesquisas, até que a versão final da ideia ficasse pronta e fosse submetida ao edital. Isto tudo aconteceu em 2008. Neste meio tempo entre o projeto ser aprovado (2009) e a verba para sua execução chegar (2010), a professora responsável pelo projeto já pertencia ao quadro da Universidade Federal Rural da Amazônia - UFRA e seus alunos da época já estavam formados. O projeto passou a ser executado então na UFRA e os alunos do CESUPA que no momento já haviam se formado foram contratados como prestadores de serviço para dar continuidade à ideia proposta anteriormente. Houve um apoio muito grande também da Gerência de Ensino da FSCMPA, o que ajudou muito na realização deste projeto.

\section{III - Apresentando o software educativo NavegaFeliz}

Para a realização deste trabalho, foi feito um estudo sobre as características e particularidades vividas pelas escalpeladas atendidas na FSCMPA, através de entrevistas com estas pacientes e com a equipe multidisciplinar responsável por seu acompanhamento. Foi feita ainda entrevista com as professoras que atuam na Classe Hospitalar para levantar os principais aspectos a serem trabalhados no software educativo, considerando que um dos objetivos iniciais do projeto era criar uma ferramenta de auxílio no processo ensino-aprendizagem das meninas escalpeladas que frequentam a referida Classe.

Em seguida, foi feita uma pesquisa de softwares educativos já existentes que pudessem auxiliar na definição das características do NavegaFeliz. Os softwares que mais ajudaram a inspirar o NavegaFeliz foram o software de quadrinhos da Turma da Mônica e o software Pintando com o Seninha, por seus recursos e características.

Tendo como base pedagógica o construtivismo de Jean Piaget (2007), foi construído o roteiro (storyboard) e o projeto da interface (wireframe) do software educativo, bem como foram criadas imagens personalizadas especialmente para retratar o dia-a-dia da população ribeirinha e amazônica, uma vez que este é o público-alvo original ao qual o software se destina.

O software foi desenvolvido conjuntamente com um estudo baseado na experiência dos usuários, pois a medida que ia sendo desenvolvido ia também sendo utilizado pelo público-alvo no Infocentro da FSCMPA na presença da equipe de 
desenvolvimento que, através de conversas e observações, ia registrando as dificuldades e ajustes necessários.

Optou-se por disponibilizar o software na Internet, ou seja, pela computação em nuvem, já que o usuário pode acessar este aplicativo de qualquer computador que esteja conectado à internet. A plataforma de desenvolvimento utilizada foi o Adobe Flash CS6 e a linguagem de programação foi o Action Script 3. O Flash é uma tecnologia de desenvolvimento para web capaz de gerar aplicativos e animações interativas, cujo projeto é compilado em um arquivo SWF que, de acordo com Braunstein (2010, p. 13), são portáteis, compactados e independentes de plataforma.

A tecnologia Flash foi adotada por deixar a aplicação leve, fazendo com que as localidades com acesso à Internet de baixa velocidade pudessem acessar a aplicação sem maiores transtornos, por não perder qualidade visual ao mudar a escala do aplicativo na tela, e, principalmente, por ser multiplataforma, funcionando em ambiente Linux, Windows ou Mac, com interface gráfica em navegador Chrome qualquer versão, Firefox versão 5.0 ou superior, Internet Explorer 5 ou superior, ou Opera versão 3.0 ou superior, bem como o plugin do flash versão 10 ou superior + internet. O NavegaFeliz também pode ser acessado via celular ou tablet que possua sistema operacional Android 2.0 ou superior e está disponível sob a licença Creative Commons.

O NavegaFeliz ${ }^{2}$ inicia com uma tela de boas vindas que fala um pouco do projeto e faz, também, referência ao prêmio Tecnologia Assistiva da Região Norte, onde o software ficou em primeiro lugar na categoria "Profissionais e Estudantes do Ensino Superior" durante o Fórum de Tecnologia Assistiva promovido pela Universidade do Estado do Pará - UEPA em outubro de 2011.

Ao clicar em qualquer parte da tela de abertura, o software abre uma tela inicial que dá acesso a 3 diferentes módulos (Fig. 2): Módulo de Produção de Histórias em Quadrinhos (Fig. 3), Módulo do Jogo da Memória e Módulo de Pintura.

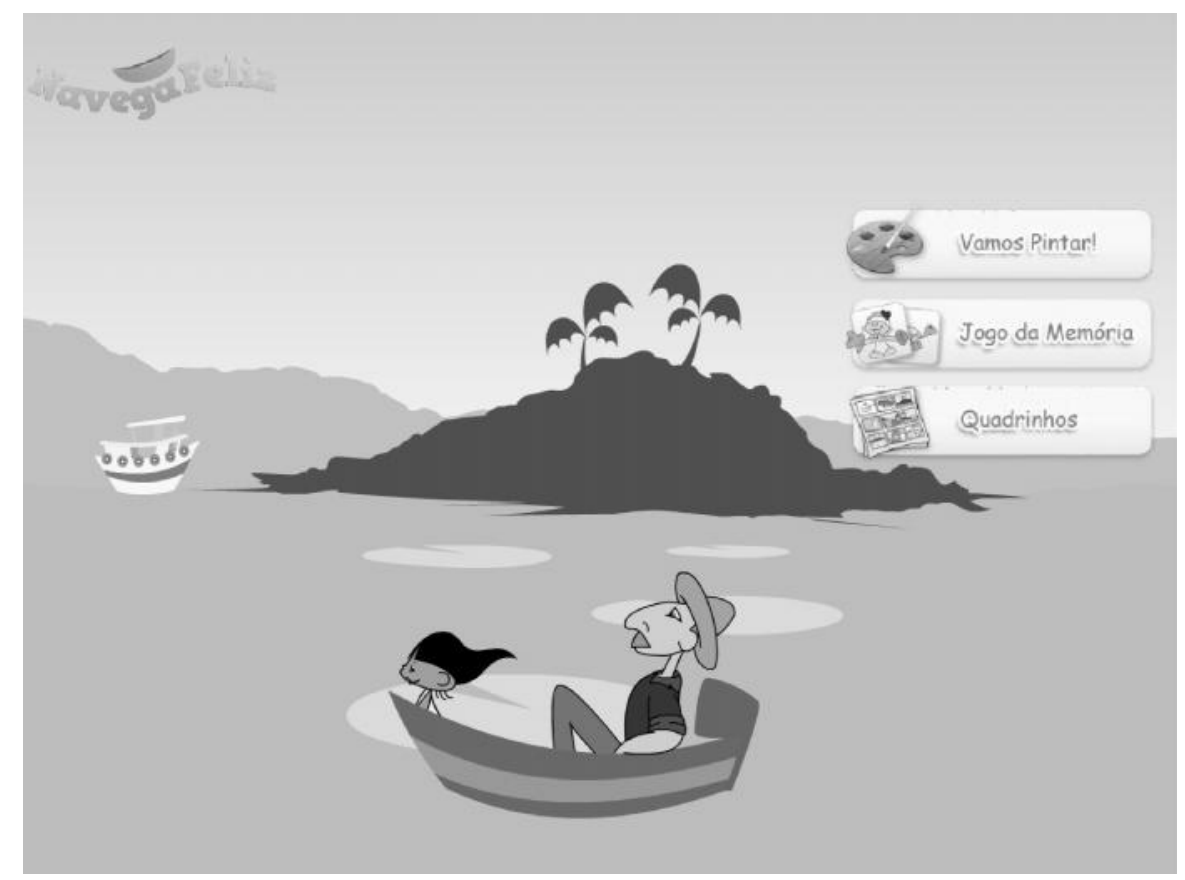

Fig. 2: Tela inicial do Navega Feliz

\footnotetext{
${ }^{2}$ Disponível em www.navegafeliz.com.br
} 
O grande diferencial deste software é que todas as atividades possuem imagens regionais, ligadas principalmente às características ribeirinhas em geral e às vítimas de escalpelamento dos rios da Amazônia, como meninas que usam chapéus e bandagem na cabeça, embarcações e rios, possibilitando que o usuário se torne sujeito ativo na ação terapêutica ao ser autor e personagem de sua própria história.

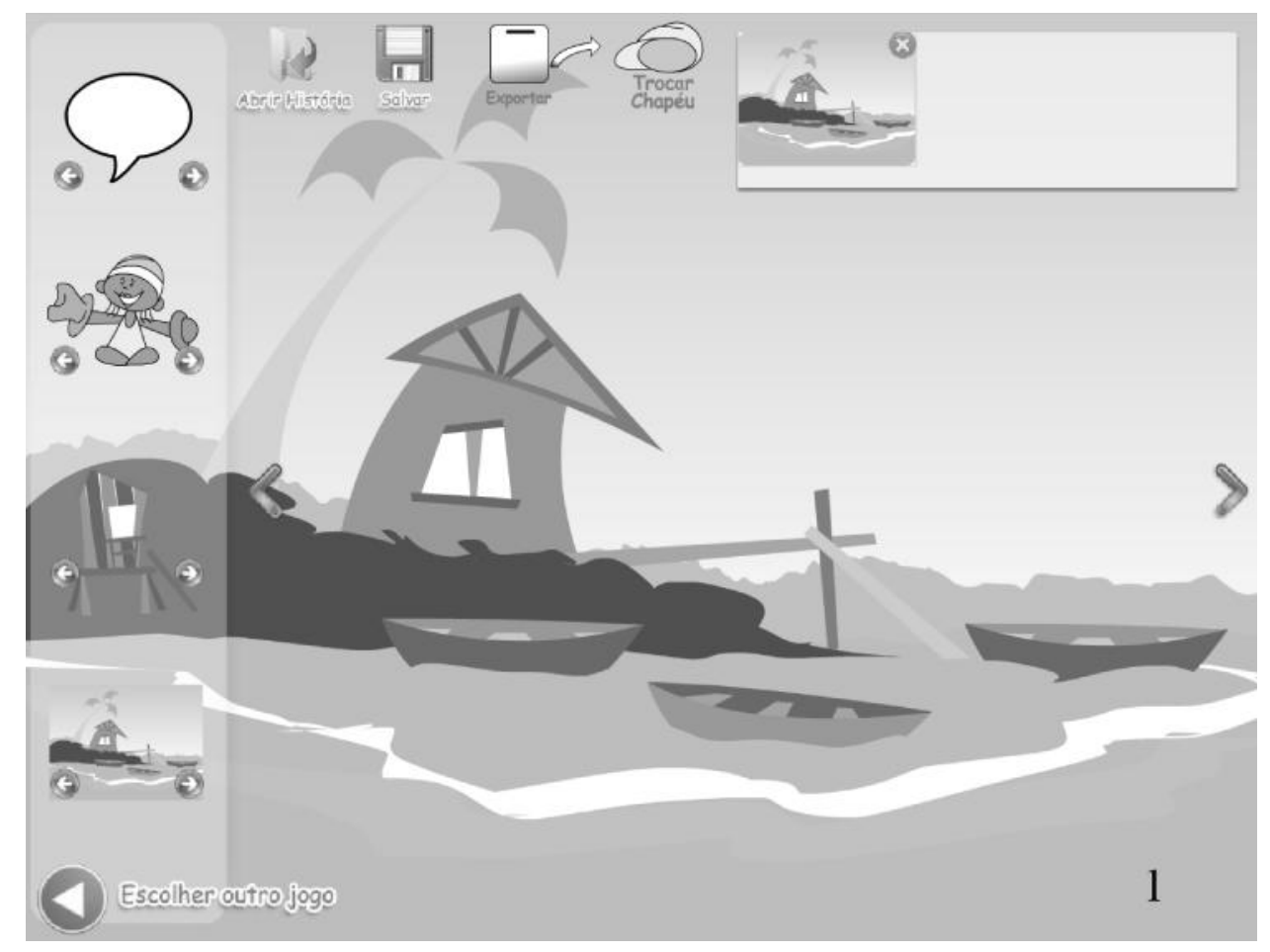

Fig. 3: Módulo de produção de histórias em quadrinhos

O Módulo de Produção de Histórias em Quadrinhos é considerado o principal por ser aberto, ou seja, por possibilitar a construção e autoria pelo próprio usuário. Este módulo possui uma barra de ferramentas que possibilita a inserção de balões, personagens, objetos e cenários diferentes ligados à região amazônica, bem como a criação de diferentes cenas para que seja produzida uma história em que a usuária possa mais facilmente e de forma despersonalizada contar sua história ou expor seus sentimentos e anseios. Após finalizar a história, ela pode ser exportada em .pdf para ser impressa ou pode ser salva em XML para ser editada posteriormente.

Para melhor compreensão da importância de se ter uma ferramenta em que as pacientes possam expressar suas ideias e pensamentos, Vale (2007, p. 68) aponta alguns sentimentos vividos por vítimas de escalpelamento:

Também observamos que não há somente sofrimento físico, mas também psíquico, pois aquelas que escaparam, sofrem intensamente, mostram-se emocionalmente fragilizadas, temerosas, envergonhadas, tristes, ansiosas e por vezes culpadas. Queixam-se de rejeição, e discriminação, apresentam sentimentos de menos valia, baixa autoestima, e em alguns casos sentem-se desejosas de isolamento e apresentam ideação suicida.

Assim, viu-se de fundamental importância desenvolver este software educativo que auxilia meninas escalpeladas não só no processo ensino-aprendizagem de temas 
trabalhados na Classe Hospitalar, mas contribui para a elevação de sua autoestima, que fica bastante abalada, bem como para a compreensão e valorização de sua história pessoal, de sua experiência de vida.

O software educativo, por sua característica lúdica, desperta ainda mais a curiosidade própria das crianças, aguça seu espírito investigativo e as leva a investigar e construir conhecimentos. Além disso, como o público-alvo em questão mora em municípios do interior do Estado, a grande maioria das pacientes não tem acesso ao computador e suas ferramentas. Neste caso, o uso do software possibilita a realização de um trabalho de inclusão digital com elas.

Outro aspecto relevante é o estímulo às relações sociais, ao aprender de forma cooperativa, uma vez que o laboratório de informática, especificamente neste caso o Infocentro, é um espaço em que as crianças estão interagindo juntas, realizando atividades que oportunizem o uso da imaginação, da criatividade, e o desenvolvimento da autonomia e da criticidade.

Com essa perspectiva e em consonância com o que afirma Lima (2004, apud Beckman e Santos, 2004, p. 21) quando diz que a terapia deve "proporcionar à criança o resgate de sua dimensão ocupacional pela manutenção da ação, da criação, da expressão e da transformação, a partir de seus hábitos cotidianos, de suas condições físicas, afetivas e sociais, tornando-a assim, não só o alvo, mas também o sujeito da ação terapêutica", é que o NavegaFeliz foi construído com estes recursos para ser trabalhado como ferramenta terapêutica, de ensino-aprendizagem e de inclusão digital e social.

O Módulo de Jogo da Memória associa a percepção visual ao desenvolvimento da memória e utiliza os personagens do módulo de histórias em quadrinhos para a formação dos pares. Ao selecionar este módulo, é possível escolher entre os níveis de dificuldade fácil, médio e difícil, cuja diferença está na quantidade de pares que aparecem para serem memorizados. Após selecionar o nível de dificuldade, os pares são mostrados por 3 segundos ao jogador (Fig. 4) e depois são escondidos para serem localizados.

No Módulo de Pintura pode ser trabalhada a criatividade, bem como as cores e as imagens ligadas à realidade das pacientes. Ao escolher o módulo de pintura, é possível definir que cenário será pintado e posteriormente pintá-lo utilizando a paleta de cores (Fig. 5). O software possibilita salvar as pinturas em formato .jpg, possibilitando sua integração com outros softwares de edição de imagem.

Todos os desenhos manipuláveis, como os que se pode pintar e os que se pode mover, usados no Módulo de Produção de Histórias em Quadrinhos e no Módulo de Pintura, são feitos diretamente no Flash, pois no formato de vetor os desenhos pesam menos na memória do computador e não perdem qualidade ao serem redimensionados. Os desenhos que compõem o layout são importados de fora do Flash, em formato .png e desenhados em Photoshop e Fireworks. 


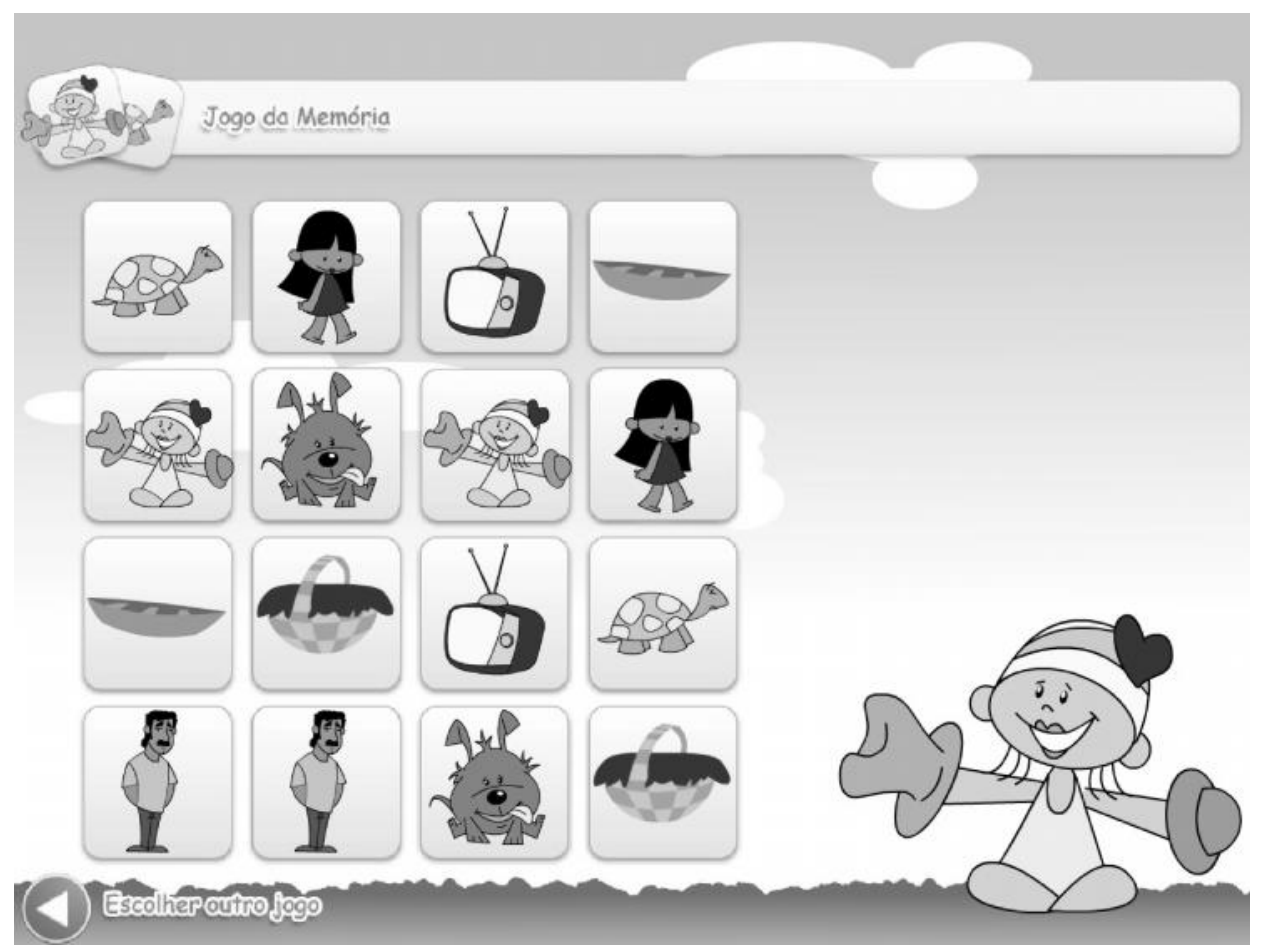

Fig. 4: Módulo de jogo da memória após escolha do nível de dificuldade

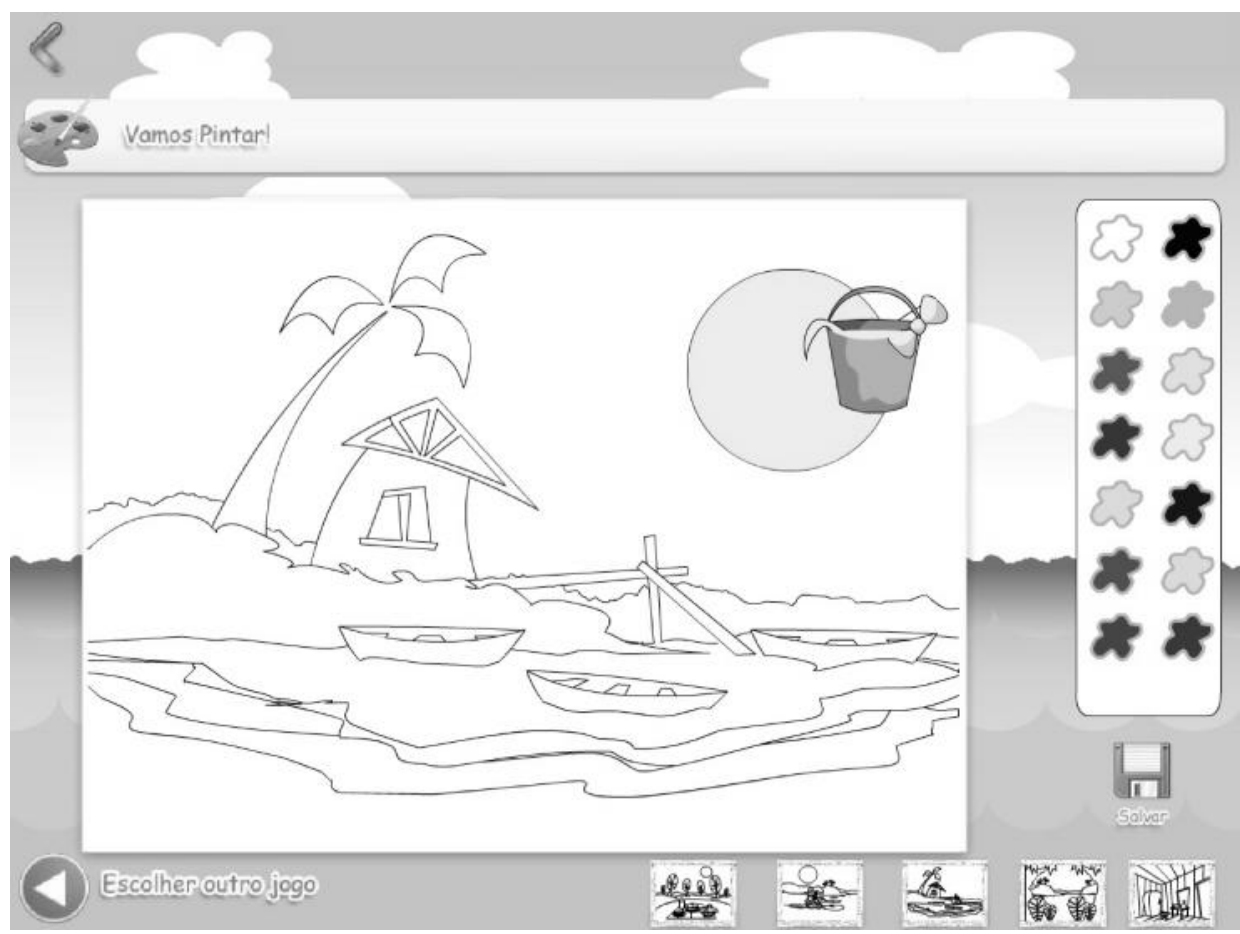

Fig. 5: Módulo de pintura após escolha do cenário

$\mathrm{Na}$ versão mais atual do software foram inseridos ainda personagens com necessidades especiais (Fig. 6), visando à ampliação do público-alvo e o trabalho com a educação inclusiva. 


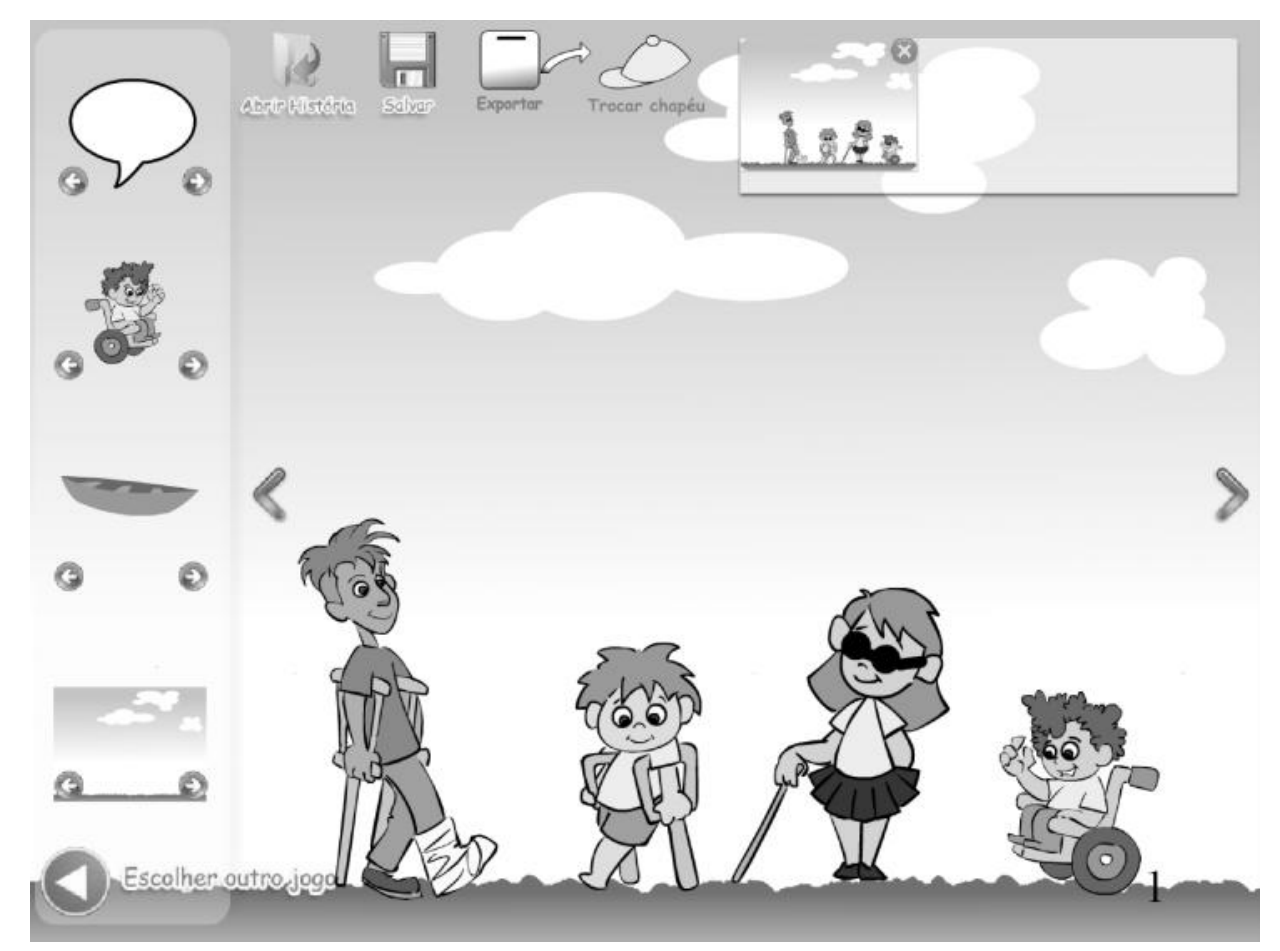

Fig. 6: Personagens com necessidades especiais

Desde que foi desenvolvido, o NavegaFeliz é utilizado no Infocentro da FSCMPA em oficinas terapêuticas que atendem a diversos pacientes da Fundação. Entretanto, apesar da aplicação deste software educativo estar focada no município de Belém, capital do Estado do Pará, onde a FSCMPA está localizada, os usuários são de diferentes municípios do interior do Estado, especialmente municípios ribeirinhos em que o meio de transporte local são pequenas embarcações, sem estrutura e mais propensas a que aconteça o acidente de escalpelamento. Estas localidades, em geral, possuem os rios como suas principais vias de acesso, como suas ruas, e os moradores são, em geral, de classe econômica baixa e com baixa escolaridade. Além disso, apesar de na maioria destas localidades já existirem Infocentros, as pessoas que chegam às oficinas terapêuticas, em geral, não sabem utilizar o computador nem a Internet.

A oficina terapêutica, dessa forma, contribui não só para o resgate da autoestima e da reinserção social, mas resgata a vontade de aprender, de se desafiar a aprender algo que para elas é muito novo e diferente, como o uso do computador. Além desta aplicação formal, feita pela equipe que projetou o NavegaFeliz, sua utilização acontece em diversos municípios de diferentes estados brasileiros abrangendo todas as regiões do Brasil, bem como em outros países, como pode ser verificado no relatório interno de acessos gerado pelo software.

Por ser um software de acesso gratuito, que pode ser utilizado de qualquer lugar que tenha internet, inclusive dos Infocentros, o NavegaFeliz atende aos públicos de todas as classes sociais e aborda um tema que, apesar de ser uma realidade da Região Amazônica, ainda é desconhecido por muitas pessoas que não vivem esta realidade. Em função deste desconhecimento, as vítimas de escalpelamento, além de ficarem com sequelas físicas graves, sofrem com o preconceito da família e da sociedade (Cardoso, 2012). 
Com a possibilidade de utilização em diferentes locais e por diferentes classes sociais, espera-se que o software ajude a desmistificar este problema, diminuindo o preconceito, e ajude a minimizar os acidentes através da sua prevenção. Dessa forma, o software traz um grande potencial em relação ao impacto social não só para as vítimas do escalpelamento, mas também para seus familiares e para a sociedade em geral.

\section{IV - Considerações Finais}

Desde 2011, ano em que as oficinas terapêuticas começaram a ser realizadas na FSMCPA, foram atendidas aproximadamente 60 pessoas de vários municípios diferentes que estavam fazendo tratamento na Fundação. O perfil desta população é de crianças, jovens e adultos, em sua maioria de baixa escolaridade, que possuem dificuldades na escrita e são analfabetos digitais.

Além desta clientela, há outro público que utiliza o NavegaFeliz que não se encontra na Fundação, mas está espalhado pelo mundo, uma vez que o software está disponível na internet e possibilita esse acesso. Através do registro interno de acesso foi verificado que mais de 500 pessoas utilizaram o software nos últimos 3 anos, não só no território brasileiro, mas em outros países como Holanda, Itália, Estados Unidos, Canadá, Grécia, Índia, Portugal e Angola.

No período de pesquisa para o desenvolvimento do software verificou-se que era necessário adotar o conceito de computação em nuvem e deixar os aplicativos disponíveis na web para acesso de qualquer lugar, uma vez que as vítimas de escalpelamento não moram na mesma localidade onde fazem tratamento e permitindo também que outros usuários possam ter acesso ao software, já que este pode ser utilizado não só em um contexto de oficina terapêutica, mas de forma livre. Como muitas localidades não possuem acesso à internet na Região Norte, foi feita uma versão off-line do software, que pode ser portada em mídia como CD ou pen drive.

Apesar de ser um aplicativo disponível em nuvem, o NavegaFeliz não possibilita que o usuário salve suas histórias em quadrinhos em nuvem também. Para salvar suas produções, ele precisa salvar um arquivo XML em disco e o compartilhamento dessa história é feito através do envio do arquivo salvo por e-mail, pen drive ou gravação local. Feito isso, o arquivo pode ser carregado novamente em qualquer outro computador para manipula-lo novamente. Essa medida foi adotada por questão de segurança e para que o software não necessitasse de acesso via login e senha, o que poderia ser um fator que dificultaria o acesso já que o principal público-alvo é usuário iniciante de informática.

Há duas funções que foram projetadas, mas ainda não foram implementadas no NavegaFeliz: a inserção de recursos de som e um vídeo animado de prevenção ao escalpelamento. Além disso, há um projeto em estudo para migração do NavegaFeliz do Adobe Flash CS6 para o HTML5 inserindo recursos de usabilidade e acessibilidade que ainda não estão implementados na versão atual.

Por ser uma ferramenta que auxilia no processo ensino-aprendizagem e na atividade terapêutica dos usuários de um hospital, com características próprias de áreas ribeirinhas, isto é, da vivência deste usuário, o software pode ser um instrumento de 
estudo e coleta de dados que produz material para pesquisa e contribui na recuperação psicossocial dos pacientes em tratamento de saúde.

É importante ressaltar que o NavegaFeliz pode ser utilizado de forma independente por qualquer pessoa e de qualquer lugar do mundo, como já enfocado anteriormente. Entretanto sua utilização em uma oficina terapêutica é muito importante para um uso direcionado ao tratamento das pacientes vítimas de escalpelamento, e o fato de possuir elementos regionais com personagens próximos ao cotidiano das pacientes promove um envolvimento e um sentimento de autoria maiores nestas usuárias do que outras ferramentas com recursos semelhantes.

Assim, o pioneirismo deste trabalho não está na simples criação de um software educativo, mas em suas características regionais, mais especificamente amazônicas e ribeirinhas, e em seu foco original de atendimento às vítimas de escalpelamento, bem como em sua potencialidade como ferramenta de inclusão digital, ferramenta de ensinoaprendizagem e ferramenta de auxílio terapêutico.

\section{Referências}

Beckman, K. A. F.; SANTOS, N. C. M. Terapia ocupacional: relato de caso com vítima de escalpelamento por eixo de motor de barco. Cadernos de Terapia Ocupacional da UFSCAR, 2004, vol. 12, n 1.

Braunstein, R. Action Script 3.0 Bible. Indianapolis: Wilwy Publishing Inc, 2010.

Cardoso, K. Vítimas de escalpelamento sofrem com abandono e preconceito da sociedade e da família. Rádio Nacional da Amazônia. Mai. 2012. Disponível em: http://radioagencianacional.ebc.com.br/materia/2012-07-05/v\%C3\%ADtimas-deescalpelamento-sofrem-com-abandono-e-preconceito-da-sociedade-e-da-fam. Acesso em: 01 Ago. 2013.

Martinelli, P. O Povo das Águas. São Paulo: Terra Virgem, 2000.

Piaget, J. Epistemologia Genética. 3 ed. São Paulo: Martins Fontes, 2007.

Vale, J. C. C. 2007. A Compreensão do Sofrimento no Escalpelamento: um estudo utilizando o grafismo e o teste das fábulas. Dissertação de Mestrado, Belém, PA. Universidade Federal do Pará, 87 p. 